\title{
The impact of the coordinating nurse role on patient satisfaction in the emergency department: a semi- experimental study
}

\author{
Mojtaba Samimi ${ }^{1,2}$, Arash Safaie ${ }^{1,2}$, Mehran Sotoodehnia ${ }^{1,2}$, Fatemeh Rasooli ${ }^{1,2}$, Atefeh Abdollahi ${ }^{1,2^{*}}$ \\ 'Prehospital and Hospital Emergency Research Center, Tehran University of Medical Sciences, Tehran, Iran \\ ${ }^{2}$ Department of Emergency Medicine, Sina Hospital, Tehran University of Medical Sciences, Tehran, Iran
}

\begin{abstract}
Received: 30 June 2020
Accepted: 29 August 2020

Published online: 8 September 2020

*Corresponding author: Atefeh Abdollahi; Department of Emergency Medicine, Sina Hospital, Hasanabad Square, Tehran, Iran. Tel: +989128077469

Email: aabdollahi@sina.tums.ac.ir

Competing interests: None.

Funding information: None.

Citation: Samimi M, Safaie A Sotoodehnia M, Rasooli F, Abdollahi A. The impact of the coordinating nurse role on patient satisfaction in the emergency department: a semi-experimental study. Journal of Emergency Practice and Trauma 2021; 7(1): 22-27. doi: 10.34172 jept.2020.31
\end{abstract}

\begin{abstract}
Objective: This study was conducted to investigate the role of an emergency nurse coordinator (ENC) in improving patient satisfaction at the emergency department (ED) in Tehran, Iran.

Methods: This was an interventional study in the field of ED management. This study was undertaken in the ED of Sina hospital in Tehran, Iran, during March 2018 until April 2019. An ENC was assigned to the ED on even days and during the next week. Also, the presence of the ENC was switched to odd days and so on. Patient satisfaction was evaluated by a questionnaire. In order to analyze data, independent T-test was used to assess the mean difference in satisfaction scores. In addition, analysis of covariance (ANCOVA) test was utilized to assess the difference in satisfaction scores after considering age, sex and triage level as confounding variables.

Results: Finally, 315 and 291 patients were allocated to the intervention (patients with ENC) and control groups (patients without ENC), respectively. The total satisfaction rate in the intervention and control groups was $63.9 \%$ and $59.3 \%$, respectively. The mean score of total satisfaction in the intervention group was significantly higher than the control group [115.1 $(S D=20.0)$ vs $106.8(S D=22.3) ; P<0.001]$. The ANCOVA analysis showed that age, sex and triage level were not confounding factors affecting the satisfaction score.

Conclusion: This study showed that the presence of the ENC in the ED can increase patient satisfaction, especially in domains related to "diagnostic and therapeutic services", "cleanliness", "cost and discharge information", "ethical and privacy issues", "admission, discharge and management services".

Keywords: Advanced practice nursing, Emergency service, Hospital, Nursing, Team
\end{abstract}

\section{Introduction}

With the introduction of modern management concepts into the medical world, emergency departments (ED) nowadays are more concerned with patient satisfaction. The special nature of the emergency department, including the nursing staff, physician issues, waiting time and etc. makes it more challenging (1-5). The results of some studies indicate poor communication with patients or rapport with nurses and other health care workers as well as inappropriate interpersonal relationships between nurses and patients in the hospital (6-8). This may be due to the lack of an appropriate framework for patient communication in hospitals (9-12).

The coordinating nurse is responsible for providing safe and high-quality care to all patients, as well as assisting medical teams to ensure safe, effective and efficient treatment to patients at all times (13-17). The nurse coordinator does a variety of tasks such as: 1) Performing or coordinating clinical activities in accordance with patient care plans, 2) Admitting patients, verifying documents, and displacing patients' stuff, 3) Monitoring and evaluating the condition of patients and helping them to develop and adjust care plans, 4) Educating patients and families on methods, treatment options, and symptom management and 5) Monitoring patient scheduling, staff guidance, and adjustments when conditions change (18).

One of the duties of the medical staff is to explain the patient's condition to them and their companions. On the other hand, timely follow-up of examinations and imaging is one of the factors affecting patient satisfaction. According to ED crowding may not perform these tasks well (19). The presence of a coordinating nurse to assist physicians and other treatment staff in performing the above-mentioned tasks will be helpful.

Different researches have been done concerning the role of a coordinating nurse and various aspects have been 
confirmed $(18,20,21)$. Thus, in many prestigious hospitals around the world, the coordinating nurse is one of the main pillars of the hospital, especially in the emergency department. The role of a coordinating nurse has been taken into consideration recently as an important issue to obtain good outcomes for patients, their families, and the health system. These outcomes include proper access to required services, improved satisfaction with service delivery, and a decrease in the hospital length of stay and unplanned re-admission (22). It is highly important to mention that there is a paucity of research concerning the role of a coordinating nurse in the ED to increase patient satisfaction in Iran. Therefore, this is the first study to investigate the role of an emergency nurse coordinator (ENC) in improving patient satisfaction at an ED in Tehran, Iran.

\section{Methods}

This was an interventional study in the field of ED management. The study population included patients referring to the ED of Sina hospital in Tehran, Iran, during a one-year period from March 2018 until April 2019. Sina hospital is an academic tertiary referral center affiliated to Tehran University of Medical Sciences (TUMS) with more than 100 patients' admission per day.

Inclusion criteria encompassed patients presenting to the ED with triage level 3, 4, or 5 [based on Emergency Severity Index (ESI)] that were admitted during morning and evening shift hours. Exclusion criteria were altered mental status, cognitive dysfunction and patients presenting to the ED or admitted during night shift hours. During the first week of the study, an ENC was assigned to the ED on even days and during the second week, the presence of an ENC was switched to odd days and so on. Patients admitted to the ED on even days in the first week were considered as intervention group, and those presenting on odd days in the first week were allocated to the control group; and vice versa in the second week and so forth. A meta-analysis conducted in 2015 in Iran showed a patient satisfaction rate of $69 \%$ (23). We assumed that ENC increased satisfaction up to $79 \%$, so the required sample size was 315 patients in each group, with 0.05 type I error and with $80 \%$ power.

In the present study, ENC was a female nurse with a bachelor degree. She had the role of communicating between physicians and patients. The ENC had responsibilities related to explaining the problems and treatment plans to the patient, following-up the tests and medical instructions, and counseling. In other words, she was responsible for the tasks neglected by physicians and nurses due to ED congestion.

Patient satisfaction was evaluated by a questionnaire consisting of 36 questions anchored on a 5-point Likert rating scale ranging from 1 to 5 . This questionnaire was a revised version of the valid and reliable PRESS GANEY questionnaire with an internal consistency of
0.889 obtained in our study. The higher scores indicate more satisfaction. This questionnaire had eight following domains:

1. Diagnostic and therapeutic services

2. Communication with non-medical staff

3. Cleanliness

4. Nursing services

5. Cost and discharge information

6. Ethical and privacy issues

7. Admission, discharge and management services

8. Other services

We presented descriptive statistics as frequency and mean with standard deviation (SD) for categorical and nominal variables, respectively. We used Chi-square or Fisher exact test to assess statistical differences of categorical variables such as sex and triage score level between study groups. We used independent $t$ test to assess the mean difference of satisfaction score in study groups. Also, analysis of covariance (ANCOVA) test was utilized to assess the difference of satisfaction score in study groups after considering age, sex and triage level as confounding variables. The satisfaction score ranged from 0 to 100 . The correlation between the score of satisfaction domain was assessed using Pearson correlation. P-value less than 0.05 was considered as statistically significant. The statistical analyses were performed using SPSS software, version 25 (SPSS Inc., Chicago, IL, USA).

\section{Results}

Of 700 patients assessed for eligibility, finally 315 and 291 patients were allocated to the intervention (patients with ENC) and control groups (patients without ENC), respectively. Data analysis of 315 and 291 patients in the intervention and control groups is shown in Figure 1. Totally, $216(68.6 \%)$ and $219(73.3 \%)$ were men in the intervention and control groups, respectively. The distribution of sex and mean of age was not significantly different between the two groups $(P>0.05)$. Also, most of the patients (90\%) were triaged in three levels and there was not a significant difference between the two groups in this regard $(P=0.555)$ (Table 1$)$.

Table 1: The distribution of sex, age and triage level between the intervention and control group

\begin{tabular}{lccc}
\hline & $\begin{array}{c}\text { Intervention group } \\
(\mathbf{n = 3 1 5})\end{array}$ & $\begin{array}{c}\text { Control group } \\
(\mathbf{n = 2 9 1})\end{array}$ & $\boldsymbol{P}$ value \\
\hline $\begin{array}{l}\text { Sex, No. (\%) } \\
\text { Male }\end{array}$ & $216(68.6)$ & $219(73.3)$ & 0.068 \\
$\quad$ Female & $99(31.4)$ & $72(24.7)$ & \\
Age, year; mean (SD) & $40.2(16.9)$ & $38.4(17.0)$ & 0.199 \\
Triage level score, No. (\%) & & & 0.555 \\
Two & $10(4.5)$ & $5(2.6)$ & \\
Three & $204(92.3)$ & $185(94.4)$ & \\
Four & $7(3.2)$ & $6(3.1)$ & \\
\hline Note: Intervention group: Patients with ENC. Control group: Patients without
\end{tabular}
ENC 


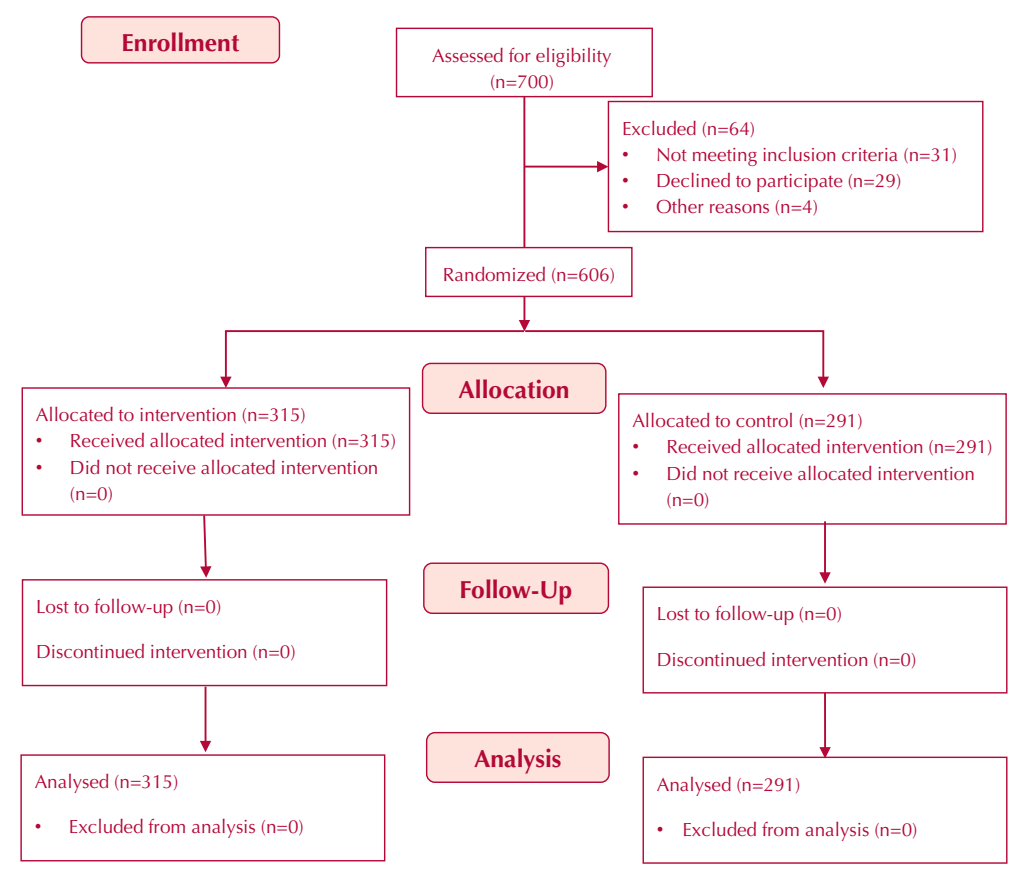

Figure 1. The flow diagram of study participants.

The mean score of total satisfaction in the intervention group was significantly higher than the control group [115.1 $(\mathrm{SD}=20.0)$ vs $106.8(\mathrm{SD}=22.3) ; P<0.001]$. The mean score was higher for all satisfaction domains in the intervention group. The difference of mean score for all domains was statistically significant $(P>0.05)$, except for "communication with non-medical staff" and "other services" domains. The ANCOVA analysis showed that age, sex and triage level were not confounding factors affecting the satisfaction score (Table 2).

The highest satisfaction, with almost $80 \%$, belonged to "communication with non-medical staff" domain. Albeit, the performed intervention did not have a role in this regard. The highest effect of intervention was seen in domains including "cost and discharge information" (55.7\% vs $62.9 \%)$, "cleanliness" (56.5\% vs $62.9 \%)$ and "admission, discharge and management services" (56.6\% vs $61.7 \%$ ), with more than $6.0 \%$ difference between the two groups. The total satisfaction score was also higher in intervention group than the control group (59.3 vs 63.9) (Figure 2).

The correlation coefficient analysis of satisfaction score between the two study groups showed that the correlation between domain was lower than 0.6 , and the intervention had considerable correlation with total satisfaction score. Therefore, intervention by affecting some domain can increase the patient's total satisfaction score (Table 3 ).

\section{Discussion}

The findings of the current study indicated that the presence of an ENC in the ED can increase patient satisfaction, especially in domains related to "diagnostic and therapeutic services", "cleanliness", "cost and discharge information", "ethical and privacy issues", and "admission, discharge and management services". The total satisfaction in the intervention and control groups was $63.9 \%$ and $59.3 \%$, respectively Research studies conducted in Iran have reported different rates for patient satisfaction in the ED. This rate was $24 \%$ in Golestan and $98.4 \%$ in Ghazvin. Also, the satisfaction rate was from $41.8 \%$ to $82.4 \%$ in Tehran (23).

The difference of the total satisfaction score in the intervention and control groups was almost 5\%. There is no other study in Iran in this regard, but other similar studies in the world have shown that the presence of a coordinating nurse can increase patient satisfaction (24-27). By the same token, research findings highlight that ENC can significantly decrease the admission time,

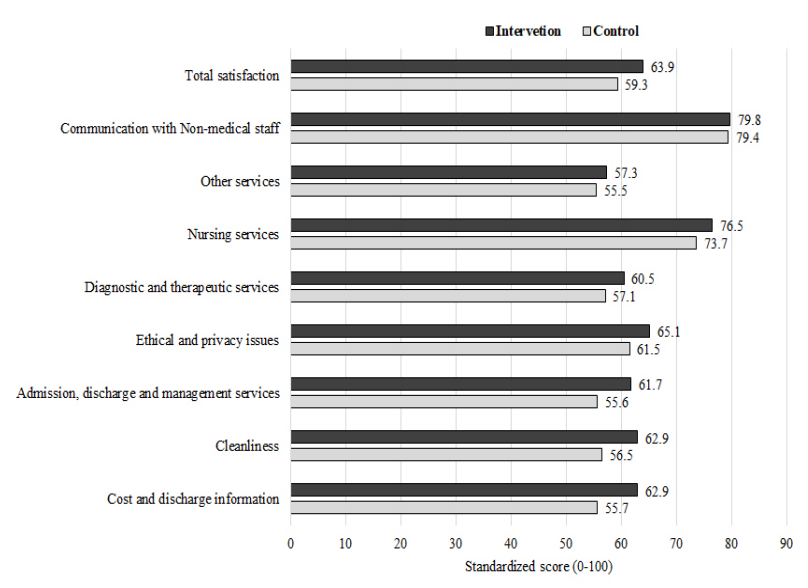

Figure 2. Satisfaction score in the intervention (patients with ENC) and control groups (patients without ENC) by domain and total score. 
Table 2. The mean difference of satisfaction score between the intervention and control groups in unadjusted and adjusted model

\begin{tabular}{|c|c|c|c|c|c|}
\hline & \multirow{2}{*}{$\begin{array}{l}\text { Intervention group } \\
\qquad(\mathrm{n}=315)\end{array}$} & \multirow{2}{*}{ Control group $(n=291)$} & \multirow{2}{*}{$\begin{array}{l}\text { Cohen }(P \\
\text { value })\end{array}$} & \multicolumn{2}{|c|}{ Adjusted model; F ( $P$ value) } \\
\hline & & & & ENC & Another variable \\
\hline Diagnostic and therapeutic services & $18.2(4.7)$ & $17.1(4.9)$ & $0.23(0.005)$ & $6.7(0.010)$ & $\begin{array}{r}\text { Age: } 1.5(0.218) \\
\text { Sex: } 1.9(0.165) \\
\text { Triage: } 0.54(0.581)\end{array}$ \\
\hline Communication with non-medical staff & $8.0(1.7)$ & $7.9(1.6)$ & $0.06(0.736)$ & $0.03(0.860)$ & $\begin{array}{c}\text { Age: } 2.1(0.146) \\
\text { Sex: } 0.16(0.688) \\
\text { Triage: } 1.2(0.289)\end{array}$ \\
\hline Cleanliness & $15.7(4.0)$ & $14.1(4.5)$ & $\begin{array}{c}0.38 \\
(<0.001)\end{array}$ & $20.4(<0.001)$ & $\begin{array}{c}\text { Age: } 1.9(0.165) \\
\text { Sex: } 1.2(0.276) \\
\text { Triage: } 0.96(0.383)\end{array}$ \\
\hline Nursing services & $11.5(2.5)$ & $11.1(2.8)$ & $(0.043)$ & $1.8(0.186)$ & $\begin{array}{c}\text { Age: } 1.8(0.187) \\
\text { Sex: } 0.08(0.776) \\
\text { Triage: } 1.6(0.183)\end{array}$ \\
\hline Cost and discharge information & $15.7(4.5)$ & $13.9(4.6)$ & $(<0.001)$ & $15.8(<0.001)$ & $\begin{array}{c}\text { Age: } 0.01(0.915) \\
\text { Sex: } 3.9(0.048) \\
\text { Triage: } 0.41(0.664)\end{array}$ \\
\hline Ethical and privacy issues & $16.3(3.9)$ & $15.4(3.9)$ & $(0.005)$ & $9.9(0.002)$ & $\begin{array}{c}\text { Age: } 1.6(0.203) \\
\text { Sex: } 4.1(0.044) \\
\text { Triage: } 4.6(0.011)\end{array}$ \\
\hline $\begin{array}{l}\text { Admission, discharge and management } \\
\text { services }\end{array}$ & $18.4(4.6)$ & $16.7(5.2)$ & $(<0.001)$ & $18.3(<0.001)$ & $\begin{array}{l}\text { Age: } 0.10(0.756) \\
\text { Sex: } 0.84(0.361) \\
\text { Triage: } 4.4(0.001)\end{array}$ \\
\hline Other services & $11.5(3.6)$ & $11.1(3.4)$ & $(0.205)$ & $1.1(0.296)$ & $\begin{array}{l}\text { Age: } 5.0(0.026) \\
\text { Sex: } 0.30(0.582) \\
\text { Triage: } 1.1(0.336)\end{array}$ \\
\hline Total satisfaction & $115.1(20.0)$ & $106.8(22.0)$ & $(<0.001)$ & $20.9(<0.001)$ & $\begin{array}{c}\text { Age: } 1.9(0.165) \\
\text { Sex: } 0.62(0.433) \\
\text { Triage: } 1.9(0.165)\end{array}$ \\
\hline
\end{tabular}

Note: Intervention group: Patients with ENC; Control group: Patients without ENC

Table 3. The correlation coefficient of satisfaction domain score between the two study groups

\begin{tabular}{|c|c|c|c|c|c|c|c|c|c|c|}
\hline & & 1 & 2 & 3 & 4 & 5 & 6 & 7 & 8 & 9 \\
\hline & & \multicolumn{9}{|c|}{ Intervention group } \\
\hline 10. Diagnostic and therapeutic services & \multirow{9}{*}{$\begin{array}{l}\text { Control } \\
\text { group }\end{array}$} & 1 & $0.249^{*}$ & $0.271^{*}$ & $0.266^{*}$ & $0.249^{*}$ & $0.526^{*}$ & $0.508^{*}$ & $0.431 *$ & $0.708^{*}$ \\
\hline 2. Communication with non-medical staff & & [00.067] & 1 & $0.282^{*}$ & $0.395^{*}$ & $0.523^{*}$ & $0.282^{*}$ & $0.387^{*}$ & $0.200^{*}$ & $0.523^{*}$ \\
\hline 3. Cleanliness & & {$\left[0.402^{*}\right]$} & {$[0.159 *]$} & 1 & $0.460^{*}$ & $0.268^{*}$ & $0.264^{*}$ & $0.399 *$ & $0.383^{*}$ & $0.632 *$ \\
\hline 4. Nursing services & & {$\left[0.302^{*}\right]$} & {$\left[0.266^{*}\right]$} & {$\left[0.403^{*}\right]$} & 1 & $0.255^{*}$ & $0.335^{*}$ & $0.442^{*}$ & $0.280^{*}$ & $0.627^{*}$ \\
\hline 5. Cost and discharge information & & {$\left[0.289^{*}\right]$} & {$\left[0.478^{*}\right]$} & {$\left[0.311^{*}\right]$} & {$[0.312 *]$} & 1 & $0.249^{*}$ & $0.466^{*}$ & $0.302^{*}$ & $0.545^{*}$ \\
\hline 6. Ethical and privacy issues & & {$\left[0.466^{*}\right]$} & {$\left[0.220^{*}\right]$} & {$\left[0.378^{*}\right]$} & {$\left[0.273^{*}\right]$} & {$\left[0.327^{*}\right]$} & 1 & $0.491^{*}$ & $0.472 *$ & $0.722^{*}$ \\
\hline 7. Admission, discharge and management services & & {$[0.473 *]$} & {$\left[0.321^{*}\right]$} & {$\left[0.436^{*}\right]$} & {$[0.382 *]$} & {$\left[0.427^{*}\right]$} & {$[0.473 *]$} & 1 & $0.466^{*}$ & $0.785^{*}$ \\
\hline 8. Other services & & [0.489*] & {$\left[0.245^{*}\right]$} & {$\left[0.468^{*}\right]$} & {$\left[0.312^{*}\right]$} & {$\left[0.428^{*}\right]$} & {$[0.572 *]$} & {$\left[0.559^{*}\right]$} & 1 & $0.710^{*}$ \\
\hline 9. Total satisfaction & & {$\left[0.700^{*}\right]$} & {$\left[0.386^{*}\right]$} & {$\left[0.692^{*}\right]$} & {$[0.551 *]$} & {$[0.609 *]$} & {$\left[0.727^{*}\right]$} & {$[0.762 *]$} & {$\left[0.816^{*}\right]$} & 1 \\
\hline
\end{tabular}

length of stay, and transfer time $(24,25,28,29)$. The current study showed that age, sex and triage level did not have a significant effect on patients' satisfaction.

In the present study, after the "cost and discharge information" domain, the greatest impact concerning the presence of an ENC was seen in "cleanliness" and "admission, discharge and management services" domains. In this regard, similar studies have shown that the presence of a coordinating nurse can improve the patient's treatment process by enhancing coordination between diagnosis and treatment, as well as enhancing treatment management and inter-departmental collaboration in hospitals (22). The ENC can facilitate care by presenting preadmission information, arranging required medical consultations, para-clinical investigations, organizing follow-up, and so many other issues $(24,30)$.

\section{Limitations}

One of the limitations of this study is the selection bias as the patients were admitted in the morning and evening shift hours. Furthermore, our study only showed the impact of an ENC on the improvement of patients' 
satisfaction in the ED. Further studies should emphasize on the effect of other factors such as interventions in emergency care services in areas such as medical care, nursing care, courtesy of staff, physical comfort, waiting time, developing the interpersonal and attitudinal skills of medical staff. Studying the effect of various factors on the satisfaction of patients can help policy makers design new protocols and implement new policies in order to improve patient management that will ultimately lead to higher patient satisfaction.

\section{Conclusion}

This study was designed to show the impact of an ENC on the level of patients' satisfaction presenting to the ED at Sina Hospital in Tehran, Iran. According to the analysis of our data, patients who were accompanied by an ENC were statistically more satisfied than the other group. This difference in satisfaction was clearly seen in all domains including the registration process, physical comfort, medical staff care and nursing care, except for non-medical care and other facilities (including transport facilities, quality of food and bed and the ability to rest).

It seems that an ENC can increase the satisfaction and meet the needs and expectations of a patient presenting to the ED by adopting appropriate communication skills with the patient, family members and hospital personnel. Also, the ENC has interactive communication with physicians and other caregiving centers such as radiology and pharmacy, thereby, reducing the time in providing the best care possible. An ENC can also help in contacting social services to meet patient's needs. As the present study is the first investigation in Iran on the impact of the ENC role on patients' satisfaction in the ED, we recommend conducting more studies on a larger population.

\section{Authors' contributions}

The conception and design of the work by AA, AS and $\mathrm{MeS}$; Data acquisition by MoS; Analysis and interpretation of data by AA and FR; Drafting the work by MoS, FR and AS; Revising it critically for important intellectual content by AA and MeS; All the authors approved the final version to be published; AND agree to be accountable for all aspects of the work in ensuring that questions related to the accuracy or integrity of any part of the work.

\section{Ethical issues}

The study protocol was approved by the ethics committee of TUMS (code: IR.TUMS.MEDICINE.REC.1397.883).

\section{Acknowledgement}

We would like to express our obligations to Prehospital and Hospital Emergency Research Center affiliated to Tehran University of Medical Sciences.

\section{References}

1. Baummer-Carr A, Nicolau DP. The challenges of patient satisfaction: influencing factors and the patient - provider relationship in the United States. Expert Rev Anti Infect Ther 2017; 15(10): 955-62. doi: 10.1080/14787210.2017.1378097.

2. Naidu A. Factors affecting patient satisfaction and healthcare quality. Int J Health Care Qual Assur 2009; 22(4): 366-81. doi: 10.1108/09526860910964834.

3. Talebpour M, Payandemehr P, Kalhor P, Abbasi N, Baratloo A. One-year analysis of the emergency department input and output; a case study of Sina hospital, Iran. Journal of Police Medicine 2019; 8(2): 87-92.

4. Momeni M, Vahidi E, Seyedhosseini J, Jarchi A, Naderpour Z, Saeedi M. Emergency overcrowding impact on the quality of care of patients presenting with acute stroke. Adv J Emerg Med 2018; 2(1): e3. doi: 10.22114/ajem.v2i1.25.

5. Nayeem A, Hinchcliffe M, Gumbs K. ED assembly: introducing a simple method of bringing emergency department staff together to facilitate improvement; a report of a real experience. Adv J Emerg Med. 2019; 3(4): e36. doi: 10.22114/ajem.v3i4.212.

6. Valizadeh L, Zamanzadeh V, Ghahramanian A, Aghajari $\mathrm{P}$, Foronda C. Factors influencing nurse-to-parent communication in culturally sensitive pediatric care: a qualitative study. Contemp Nurse 2017; 53(4): 474-88. doi: 10.1080/10376178.2017.1409644.

7. Lamiani G, Furey A. Teaching nurses how to teach: an evaluation of a workshop on patient education. Patient Educ Couns 2009; 75(2): 270-3. doi: 10.1016/j.pec.2008.09.022.

8. Kashani P, Mirbaha S, Forouzanfar MM, Meschi F, Baratloo A. The prevalence of personality disorders among emergency nurses based on MMPI-2 questionnaire; a cross-sectional study. Emerg (Tehran) 2017; 5(1): e17.

9. Shahriari M, Mohammadi E, Abbaszadeh A, Bahrami M, Fooladi MM. Perceived ethical values by Iranian nurses. Nurs Ethics 2012; 19(1): 30-44. doi: 10.1177/0969733011408169.

10. Morowati Sharifabad MA, Rafati Fard M, Fattahi Ardakani M, Dehghani Ahmadabad A, Sotudeh A. Determinants of effective nurse-patient communication based on the health action process approach in Yazd hospitals. Horm Mol Biol Clin Investig 2019; 40(3). doi: 10.1515/hmbci-2019-0026.

11. Mirbaha S, Kashani P, Arhami Dolatabadi A, Amini A, Meschi F, Baratloo A. The prevalence of personality disorders in nurses: role of the workplace environment. J Emerg Pract Trauma 2017; 3(2): 59-63. doi: 10.15171/ jept.2017.22.

12. Esmaeili R, Aghili SM, Sedaghat M, Afzalimoghaddam M. Causes of prolonged emergency department stay; a crosssectional action research. Adv J Emerg Med 2018; 2(2): e18. doi: 10.22114/ajem.v0i0.58.

13. Williams G, Hughes V, Timms J, Raftery C. Emergency nurse as hospital clinical team coordinator--shining a light into the night. Australas Emerg Nurs J 2012; 15(4): 245-51. doi: 10.1016/j.aenj.2012.08.001.

14. Arhami Dolatabadi A, Maleki M, Memary E, Kariman H, Shojaee M, Baratloo A. The use of emergency department services for non-emergency conditions. HealthMED 2017; 11(1): 3-9.

15. Seyedhosseini-Davarani S, Hesari E, Afzalimoghadam M, Tavakoli N, Seyedhosseini J, Hossein-Nejed H, et al. Validity of triage performed by nurses educated by train-oftrainer workshop participants; a cross-sectional study for 
assessment of cascade training system. Adv J Emerg Med 2020; 4(1): e2. doi: 10.22114/ajem.v0i0.127.

16. Haroutunian P, Alsabri M, Kerdiles FJ, Adel Ahmed Abdullah H, Bellou A. Analysis of factors and medical errors involved in patient complaints in a European emergency department. Adv J Emerg Med 2018; 2(1): e4. doi: 10.22114/AJEM.v0i0.34.

17. Hajzargarbashi E, Rashedi R, Pourafzali S, Esmailian M. Waiting time for specialist consultation and visit requested in the emergency department; a cross-sectional study. Adv J Emerg Med 2019; 3(2): e15. doi: 10.22114/ajem.v3i2.136.

18. Henderson DP. Role of "nurse coordinator for pediatric emergency care": important part of new consensus guidelines. J Emerg Nurs 2002; 28(1): 73-7. doi: 10.1067/ men.2002.121838.

19. Frank C, Elmqvist C. Staff strategies for dealing with care situations at an emergency department. Scand J Caring Sci 2019. doi: $10.1111 /$ scs.12812.

20. Bourdolle É, Mitha N, Guillem P, Zerhouni N, Gavazzi G. [Role of the nurse coordinator in geriatric oncology]. Rev Infirm 2019; 68(249): 25-6. doi: 10.1016/j. revinf.2019.02.007.

21. Al-Kaiyat MO. Precision coordination: the growing role of the nurse coordinator in the Era of personalized medicine. Clin J Oncol Nurs 2018; 22(1): 113-5. doi: 10.1188/18. cjon.113-115.

22. Nutt M, Hungerford C. Nurse care coordinators: definitions and scope of practice. Contemp Nurse 2010; 36(1-2): 71-81. doi: 10.5172/conu.2010.36.1-2.071.

23. Kardanmoghadam V, Movahednia N, Movahednia M, Nekoei-Moghadam M, Amiresmaili M, Moosazadeh M, et al. Determining patients' satisfaction level with hospital emergency rooms in Iran: a meta-analysis. Glob J Health Sci 2015; 7(4): 260-9. doi: 10.5539/gjhs.v7n4p260.

24. Forster AJ, Clark HD, Menard A, Dupuis N, Chernish R, Chandok N, et al. Effect of a nurse team coordinator on outcomes for hospitalized medicine patients. Am J Med 2005; 118(10): 1148-53. doi: 10.1016/j.amjmed.2005.04.019.

25. Asha SE, Ajami A. Improvement in emergency department length of stay using a nurse-led 'emergency journey coordinator': a before/after study. Emerg Med Australas 2014; 26(2): 158-63. doi: 10.1111/1742-6723.12201.

26. Karagun O, Yesilagac H, Gulalp B, Gokel Y. What can we do to improve patient satisfaction in the emergency department? a prospective study in a Turkish university hospital. Adv J Emerg Med 2018; 2(4): e41. doi: 10.22114/ AJEM.v0i0.94.

27. Mohammadi-Sardo MR, Salehi S. Emergency department patient satisfaction assessment using modified servqual model; a cross-sectional study. Adv J Emerg Med 2019; 3(1): e3. doi: 10.22114/AJEM.v0i0.107.

28. Moher D, Weinberg A, Hanlon R, Runnalls K. Effects of a medical team coordinator on length of hospital stay. Cmaj 1992; 146(4): 511-5.

29. Preethy S, Xavier T, Reghunathan N, Robin M, Agrawal D. Impact of an emergency nurse coordinator on work flow optimization in an emergency department in Delhi, India. Stud Health Technol Inform 2016; 225: 875-6.

30. Taylor C, Benger JR. Patient satisfaction in emergency medicine. Emerg Med J 2004; 21(5): 528-32. doi: 10.1136/ emj.2002.003723. 